\title{
测绘工程测量中测绘新技术的应用研究
}

叶澜

天津市远景测绘有限公司

DOI:10.32629/ems.v2i2.732

[摘要] 随着人们对于生活质量的要求不断增高,因此也使得人们逐渐重视各种质量安全问题。因此在工程建设中, 对于工程测量的精度要求逐渐增高,这也就使得测绘工程测量技术不断的融入新的科技,从而使测量技术得到相应的 提升。在测绘技术的不断优化与变革中,测绘新技术的出现为工程测量提供了较好的保障。本文讲述了测绘工程的重 要意义,从而引出当前测绘新技术的主要作用与优势,并对当前测绘工程中的测绘心技术应用进行分析,对测绘新技 术的发展前景进行探讨,充分发挥测绘新技术的重要作用,提升工程测量数据的准确性,促进工程建设的良好进行。

[关键词] 测绘工程测量;测绘新技术;应用

在当前的工程建设过程中, 进行相应的测绘工程是 工程建设的必要项目,对工程建设起到重要的参考作用。 通过进行测绘工程测量, 充分了解建设现场的相关数据 信息,从而能够更加合理的去对建设场地进行分布规划, 为后期的工程建设提供有力的基础保障。同时测绘测量 技术还对后期工程在建设过程中有着重要作用, 测绘能 够为工程构建的安装和定位提供重要的数据信息, 使建 设更加的准确,从而提升工程建设的施工效率和质量。而 当前测绘工程测量中测绘新技术的发展使得其能够为

能,能够不断完善和优化项目设计, 最终目的是能够实现 整体项目质量的要求, 实现更好的效果体现。

\section{4 掌握招投标阶段的工程造价管理}

作为施工企业,需要详细掌握工程项目标准,并根据 自身施工能力进行工程造价管理,通过详细的计算,需要 施工企业能够有效制定招投标方案，从而通过三个方面 的制定,最终确定投标价格:成本,利润,税金。围绕这三个 因素,需要施工企业能够合理安排资金使用情况, 并为工 程建设创造更加合理的方式, 确保整体工程能够顺利进 行。

\section{5 监管施工阶段的工程造价管理}

施工阶段作为工程项目最重要的阶段, 施工企业要 树立正确的管理意识, 将工程质量作为施工阶段的重要 目标。在进行工程建设时,需要施工企业能够正确理解设 计内容, 同时将自身的资源利用程度发挥到最大, 并合理 安排施工现场,增加工程建设效率, 使每个阶段的施工过 程, 都能符合工程造价要求,并通过严格的管理控制措施, 实现工程造价目标的实现。

\section{5 结束语}

建筑工程造价管理是从管理水平上对建筑工程进 行整体的把握, 然后为企业和施工方确定在建造时的具 体的造价以便于准备资金, 其重点是在保证企业获得足
工程提供高精度的数据信息, 有效的保证工程建设的质 量, 从而更加促进工程建设的良好进行。随着科学技术的 发展, 当前的测绘新技术主要包括遥感技术、数字化技术 和 GPS 测量技术。这些技术在工程建设的测绘工程测量 中的应用, 使得工程中的数据更加的准确, 从而使工程建 设的相关数据更加的科学, 保证工程建设的质量。

\section{1 测绘工程的重要作用}

我国各个行业都会运用到相应的测绘工程技术, 通 过测绘技术的运用, 可以有效的提升施工水平和施工精

够的利益的基础上顺利完成整个工程。这几年, 建筑工程 发展达到了瓶颈, 这就要求建筑企业一定要开始重视工 程造价控制与管理工作。在进行建筑项目管理时, 工程造 价的管理与控制关乎企业的整体成本和利润, 想要在激 烈的社会竞争中占据绝对的领导位置, 就必须坚持做好 工程造价的管理与控制, 为企业的高速发展打下坚实的 基础。

\section{[参考文献]}

[1]王圣华,冯权升.加强工程造价管理有效地控制 工程造价[J].工程技术(文摘版),2016(9): 142 .

[2]张明文.加强工程造价管理有效控制工程造价的 研究[J]. 黑龙江科学,2018(22): $90+91$.

[3]朱莹. 建筑工程造价控制的存在问题及优化措施 研究 [J]. 居舍,2018(14): 192.

[4]兰星宇.浅谈如何做好建筑工程项目造价管理控 制[J]. 居舍,2017(28): 107.

[5]寇翠玲.浅析建筑工程项目造价的管理与控制 [J].江西建材,2015(18):231 + 232.

\section{作者简介}

姓名: 张海潮; 性别: 男; 民族: 汉; 籍贯: 石家庄; 身 份证号:130929198602120374 
准度。而在科学技术的发展下,测绘技术与数字技术信息 技术逐渐的的融合发展，使得测绘技术逐渐的完善与优 化, 有效的提升了测量的质量。在相应的工程建设初期, 需要从工程建设的实际特点出发, 并根据工程设计去进 行相应的测绘方案的设计, 所设计的测绘方案需要严格 保证测绘精度从而才能促进方案的科学性与合理性。在 测绘过程中需要对实地的地形地势进行观察与勘测, 从 而去对测绘方案做出相应的优化与调整。同时还要对测 绘地区的相关水文环境进行测绘, 从而使测绘方案的设 计范围更加广阔与全面, 保证所进行的测绘工程能够提 供较为完整的信息。通过测绘工程所得到的相关数据能 够对实际施工方案起到重要的参考依据作用, 施工人员 能够充分了解测绘地区的地质情况, 从而避免选择到不 合适的施工工艺从而对地质环境造成损坏, 同时也引发 相应的安全事故。对建筑物的沉降预测需要运用到测绘 工程所测量出的相关资料, 从而使测绘评估更加的准确 和科学, 有效地避免建筑物建设完成后出现沉降现象而 导致建筑物出现裂缝等问题。由此可见,测绘工程的准确 性能够有效的保证施工的安全有序进行, 同时也能保证 施工质量。而不断地对测绘技术进程优化与更新,其不断 融人新的科学技术, 从而提升测绘技术的准确性,进一步 提升测绘质量。

\section{2 测绘新技术的作用与优势}

2.1 地理信息系统的建设

通过对测绘新技术的应用, 可以对较多的数据信息 进行收集和整理,从而构建成相应的地理信息系统,如当 前人们所运用的各种地图线路, 这种地理信息系统为人 们的生活提供了便利, 保障了人们的日常出行。通过测绘 新技术中两种系统所获得的数据信息的分析和处理,使 得建立的地理信息系统可以有效的满足建筑工程测量 工作中对精准数据的需求, 促进建筑工程的开展。测绘新 技术所建设的地理信息系统可以有效的向城市规划提 供相应的数据信息, 从而使城市化发展在规划过程中能 够获得有效的参考依据, 保证城市规划的科学性和合理 性。

\section{2 推进城市信息化管理}

当前经济水平的发展推动着工程建设的不断扩大, 而在工程建设过程中往往会遇到一些地质性问题, 从而 对施工的开展造成相应的影响, 增加施工难度, 使得工程 建设需要耗费大量的成本。因此通过利用测绘新技术对 施工范围内的地址条件和地质状况进行有效的测量和 分析, 使相应的施工人员能够了解当前施工区域的地质 信息,从而选择适合施工的施工工艺, 以便于能够使工程 顺利开展。在工程建设施工中运用测绘新技术, 也能够为 城市规划提供较为准确的数据信息, 并对所测量的数据 进行整理和标注, 从而保证本市规划的质量, 推进城市信
文章类型: 论文 | 刊号 ( ISSN ):2705-0637(P)/2705-0645(O)

息化的建设。通过运用测绘新技术对施工区域进行测量, 使得相应的工作人员能够更加直观地了解施工区的实 际情况,从而有效地保证了施工的顺利进行,提升工程质 量,同时也能够为城市信息化管理提供充足的数据支持。

\section{3 测绘新技术与应用}

3.1 遥感测绘技术、地理信息技术和全球定位技术

通过应用卫星与摄影技术去去获取相应的准确的 数据信息是遥感测绘技术的主要工作, 通过遥感测绘测 量技术可以为测绘工程提供较为准确的数据信息和图 形信息,同时将测绘工程和实际测量的效率提升,保证测 绘工程的顺利开展。地理信息技术是通过将互联网技术 和遥感技术进行融合, 充分发挥测绘数据信息的处理与 存储的优势，地理信息技术可以对空间环境和相应的信 息进行测量,同时可以收集和分析所获取的数据信息。同 时通过地理信息技术的应用还可以对复杂地形进行数 据获取,并能够进行预测与预报,从而能够有效的保证测 绘的质量和水平,促进测绘工程的开展。全球定位技术的 应用范围较广，且全球定位技术所获取的数据信息准确 性较高,因此可以保证相应的建筑工程的质量和安全。通 过运用全球定位技术可以对测量工程进行实时的监督, 并完成人力所不能完成的监测工作，在进行建设过程中 还能够采集与收集相应的信息, 对工程的建设提供较为 有利的参考依据。同时还可以通过计算机技术对所监测 所获取的数据信息进行分析, 从而使工程的建设能够得 到良好的改善,有效地将工程建设工期缩短,降低工程建 设成本的同时也能保证工程施工质量。

\section{2 数字化绘图技术}

数字化绘图技术是将测绘工程测量的数据信息进 行系统的整合, 然后再利用相关的计算机技术将整合的 内容制成相应的图像, 从而为建筑工程的开展提供相应 的参考依据, 是管理人员能够尽快的对相应的问题进行 审核,同时为建筑项目提供较为精准的数据信息。数字化 绘图技术的应用可以降低传统测绘技术的误差现象, 保 证数据信息的完整性与精准性, 提升测绘工程测量结果 的质量。

\section{3 摄影测量测绘技术}

摄影,测量测绘技术所捕捉的数据信息较为精准,同 时也能够将测量的信息以图像的方式展现出来, 而通过 图像的方式可以使数据信息的展现更加的简单明了, 可 以充分的了解数据信息的细节, 应用摄影测量测绘技术 可以对所运用的资源进行有效合理的配置, 降低资源的 浪费现象,从而使测绘工程成本得到有效控制,保证建筑 工程的顺利开展,推动建筑企业的经济发展。

\section{4 工程测绘中测绘新技术的具体应用}

4.1 市政工程建设的应用

进行市政工程建设时,网会通过采用摄影测量技术, 
去对城市的地形路网进行测绘, 充分运用无人机低空飞 行去对公路的路网以及相关建筑物的分布状况进行信 息数据的采集，摄影测量技术所采集的相关数据信息较 为精密全面, 能够为城市市政工程建设提供较为全面的 参考资料, 通过运用资料是路网的重新规划更加的科学 合理。

\section{2 水利工程中的应用}

需要进行水利工程建设时, 就需要对相关区域范围 内的地形地势做详细的测量, 充分掌握相关数据以便促 进水利工程建设的安全开展。因此采用数字化的测绘技 术能够使相关技术人员充分了解水利工程建设的具体 范围和精细数据,从而能形成较为准确的范围勘测图。再 利用遥感技术在数字化的测绘技术所勘察的基础之上 去进行测绘, 取相关测绘资料能够使施工人员掌握水利 工程建设区的地形地势, 从而能制定出较为科学合理的 施工方案, 从而有效的控制水利工程的施工质量。水利工 程建设的施工方案需要较为完整的工程图和地形图去 作为参考依据, 而数字化测绘技术中的自动测绘功能就 可以得出相应的图像资料,能对这些资料进行存储,因而 能够使在施工方案设计过程中, 提供充足的图像资料, 使 得施工方案更加的科学合理。

\section{3 地籍测量中的应用}

地级测量的测量范围较大,面积较广, 因此就可以同 时采用摄影测量技术和数字化测量技术去完成相应的 测量工作, 从而保证测量数据的准确性和全面性。通过数 字化测量技术可以对整体范围内的地形地势进行数据 信息的收集和处理, 而采用摄影测量技术就能够明确地 获取区域内当前的土地利用现状信息, 这两种测绘技术 相结合就可以减少人工测量的工作量大、工作难度大的 现象。通过采用摄影测量技术和数字化测量技术, 能够充 分了解当前城镇土地的现状, 为我国土地信息管理建设

\section{提供了较为准确的数据。}

\section{5 测绘新技术的发展前景}

经济水平的快速发展与推动的各项工程的建设不 断开展, 因此测绘新技术的出现就可以使工程建设中的 数据更加的准确, 从而有力地保障了工程建设的质量。同 时测绘工程技术也代表着我国的科研技术水平, 同时对 经济发展也有重要的作用, 因此测绘新技术也有着巨大 的发展潜力。测绘新技术的优势使得测绘新技术能够在 各种行业中运, 因此测绘新技术的使用范围较广。同时随 着科学技术的不断发展, 也会使测绘新技术逐渐的融人 各种新的科学技术, 因此也会使得测绘新技术更加的智 能化, 使测量出的数据更加的精准, 从而促进测绘新技术 的应用与发展。

\section{6 总结}

随着社会科学技术的不断发展, 与人们逐渐认识到 工程测量的重要作用, 使得越来越多的科学技术逐渐融 人到工程测量中, 从而有效的提升工程测量数据结果的 质量, 有效的为相关的工程建设提供较为准确的数据信 息。通过对当前的测绘新技术进行分析, 讲述在工程测量 中对这些技术的应用。同时根据这些相应的运用情况, 对 测绘新技术的发展前景进行分析。通过发展和运用测绘 新技术, 使得工程测量的结果更加的准确, 为工程建设提 供较为精准的数据, 从而保障工程建设的质量。

\section{[参考文献]}

[1]陈浩, 苏文强.测绘新技术在测绘工程测量中的 应用分析[J].智能城市,2020,6(08):79+80.

[2]董尔银.测绘工程测量技术的发展与应用分析 [J].工程技术研究,2020,5(08): $111+112$.

[3]徐勇, 徐小芳, 田剑. 测绘工程测量中无人机遥感 技术的应用[J]. 工程技术研究,2020,5(08): 117+1 18 . 